\title{
Competitiveness of a native Rhizobium leguminosarum biovar trifolii strain for nodule occupancy is manifested during infection
}

\author{
Samuel Duodu • Caroline Brophy • \\ John Connolly • Mette M. Svenning
}

Received: 14 July 2008 / Accepted: 27 October 2008 / Published online: 28 November 2008

(C) Springer Science + Business Media B.V. 2008

\begin{abstract}
The stages in the nodulation process that determined the competitiveness of $R$. leguminosarum bv. trifolii (Rlt) strain 20-15, which proved to be highly competitive for nodulation in Iceland fields tests over several years, is analysed. White clover (Trifolium repens L.) roots were inoculated with inoculum mixtures containing three strains (Rlt 20-15, Rlt 8-9 and Rlt 32-28) in different proportions and cell densities. Competitiveness in root colonization, formation of infection threads and nodule development was assessed for Rlt 20-15 and its weakest competitor, Rlt
\end{abstract}

Responsible Editor: Harsh P. Bais.

S. Duodu $\cdot$ M. M. Svenning $(\bowtie)$

Department of Biology, University of Tromsø,

N-9037 Tromsø, Norway

e-mail: Mette.svenning@ib.uit.no

C. Brophy $\cdot$ J. Connolly

UCD School of Mathematical Sciences,

Ecological and Environmental Modelling Group,

University College Dublin,

Dublin 4, Ireland

Present address:

S. Duodu

National Veterinary Institute,

Oslo, Norway

Present address:

C. Brophy

Department of Mathematics,

National University of Ireland,

Maynooth, Co Kildare, Ireland
32-28. ERIC-polymerase chain reaction (PCR) DNA fingerprinting was used to identify inoculated strains recovered from root surfaces and individual nodules. GFP or DsRed tagged strains were used to determine identity in root hairs and nodules. Both strains colonized the root equally at all inoculum ratios tested. But, Rlt 2015 initiated significantly more infection threads and formed more nodules than Rlt 32-28. These results show that Rlt 20-15 expresses its nodulation competitiveness during infection, either at infection thread initiation or during successive growth in the infection threads. The data presented support earlier observations that this strain competed well in the field in spite of its inferior ability to survive in the soil.

Keywords Rhizobium leguminosarum bv. trifolii . Competitiveness · Nodule occupancy $\cdot$ Root colonization · Infection threads · Trifolium repens

\section{Introduction}

Rhizobia are soil bacteria that form symbiotic associations with leguminous plant species, with a unique feature of forming root nodules in which the bacteria reduce atmospheric nitrogen to ammonia for assimilation by the host legume (Merrick and Edwards 1995). For more than a century, agricultural practices have tried to take advantage of this symbiosis by inoculating legumes with more effective nitrogen fixing strains with the aim of improving crop growth without 
addition of chemical nitrogen fertilisers. However, little success has been achieved from such practices because many strains used as inoculants lack competitive fitness to infect and occupy nodules of target host plants (Brockwell et al. 1995).

Competition for nodulation is a quantitative phenotype, which determines the ability of certain Rhizobium strains to dominate in the nodules of a given legume host in competition with other strains present in the root rhizosphere (Dowling and Broughton 1986). This may be a characteristic property of a strain that can be expressed only during interaction with the legume host (Triplett and Sadowsky 1992). As yet, we know very little about the molecular mechanisms that determine the relative competitiveness between the nodulating strains. We also lack a comprehensive understanding of which stage(s) in the nodulation process is most critical for the success or failure of a given strain to occupy the nodule. Several factors have been implicated in competitive nodulation namely motility and chemotaxis, antibiotic production, selective substrate utilisation, faster growth and colonization of the rhizosphere, rate of infection, cell surface determinants and nodule forming efficiency (reviewed in Vlassak and Vanderleyden 1997; Sessitsch et al. 2002). The data generated from studying these factors are however inconsistent and do not hold for all Rhizobium-legume systems. For example, while the numbers of rhizobia in the root rhizosphere of soybean (Glycine max L.) and annual medics (Medicago spp.) positively correlated with higher nodule occupancy (Herridge et al. 1984; Brockwell et al. 1989; Young and Brockwell 1992), no such correlation was found to exist in clover (Trifolium spp) by Leung et al. (1994). A more recent study also provided a genetic evidence to show that mutant strains impaired in root colonisation displayed better nodulation competitiveness than their isogenic parental strain on alfalfa (M. sativa) roots (Jensen et al. 2005). In addition to genetic traits of the bacteria, many other factors, including the plant genotype, soil $\mathrm{pH}$, temperature, nitrogen concentration, and microbial antagonisms among others, have been shown to influence strain competitiveness for nodule occupancy (Vlassak and Vanderleyden 1997).

Our previous studies showed significant differences in nodule occupancy among three unmarked $R$. leguminosarum biovar trifolii (hereafter abbreviated as Rlt) strains introduced into a field in Iceland, initially devoid of clover nodulating rhizobia (Svenning et al. 2001). Among these strains, Rlt 20-15 consistently occupied $80-90 \%$ of the nodules tested; while Rlt 8-9 and Rlt 32-28 occupied 9-18\% and 3\%, respectively, of the nodules sampled from white clover (T. repens L.). This nodulation competitiveness pattern has been maintained in the field over a decade, and also shown to be consistent across a wide range of clover genotypes including the red clover ( $T$. pratense L.) cultivar Betty (Duodu et al. 2007). Analysis of the relative population of these three strains in the field revealed that the high nodule occupancy of the dominating strain (Rlt 20-15) in field isolates is due to its greater competitiveness rather than its survival in the soil environment (Duodu et al. 2005). In fact Rlt 32-28 was present in much higher numbers in the soil (even in the absence of clover) than Rlt 20-15, which appears to be a poor saprophyte.

In this study we have undertaken a systematic in vitro analysis to determine the critical stages in the nodulation process where Rlt 20-15 strain's competitiveness is determined. We report the results of the comparison between Rlt 20-15 (strongest competitor) and Rlt 32-28 (weakest competitor) for competitive root surface colonization, infection thread formation and nodule development under controlled experimental conditions. Since the strains are unmarked, the rep PCR (polymerase chain reaction) fingerprinting technique was used to identify the recovered isolates from root surfaces and nodules in the root colonisation and nodule forming efficiency experiments. Strains were tagged with green and DsRed fluorescent proteins (Gage 2002), to follow their invasion of the root hair inside the infection threads. This study provides evidence to show that greater nodule occupancy by the competitive strain Rlt 20-15 results from higher number of infections induced by this strain rather than through better colonisation of the root rhizosphere.

\section{Materials and methods}

Plant material and seed surface sterilization

White clover (T. repens cv. HoKv 9238) seeds were obtained from Plant Research Centre, Holt, Tromsø. This cultivar is a self incompatible outcrossing polyploid, not clonally propagated and therefore not a genetically uniform population. The seeds were surface sterilised by immersion in 95\% ethanol for $10 \mathrm{~s}$, and in $3 \%(\mathrm{v} / \mathrm{v})$ hydrogen peroxide (Merck, 
Whitehouse Station, NJ, USA.) solution for a period of $5 \mathrm{~min}$. To drain off the peroxide, the seeds were rinsed with six changes of sterile distilled water. They were allowed to imbibe in sterile water for $4 \mathrm{~h}$, (Somasegaran and Hoben 1994), and then incubated on $0.9 \%$ water agar for germination. Prior to germination, the seeds were pre-conditioned in the dark at $4^{\circ} \mathrm{C}$ overnight at room temperature.

Rhizobium isolates and preparation of inocula

The three unmarked strains (Rlt 20-15, Rlt 8-9 and Rlt 32-28) used in this study were selected from our natural collections of soil populations from a site in Tromsø. Selections were based on their high nitrogen fixing ability and distinct PCR fingerprint patterns. Pure cultures of these strains were grown to early stationary phase cultures in Tryptone Yeast (TY,) liquid media at $27^{\circ} \mathrm{C}(115 \mathrm{rpm})$ for $4 \mathrm{~d}$. The cells were harvested by centrifugation ( $5 \mathrm{~min}$ at $10,000 \mathrm{~g}$ ) at room temperature and washed two times with sterile water. This was followed by determination of the optical densities at $600 \mathrm{~nm}\left(\mathrm{OD}_{600}\right)$ with Spectra Max 250 Molecular Device (Global Medical Instrumentation Inc, Albertville, Minnesota, USA). The actual number of cells in the inoculum for each strain was determined by plating each suspension on TY plates and incubating for $4 \mathrm{~d}$ at $27^{\circ} \mathrm{C}$.

Nodule occupancy test

In vitro nodule occupancy tests were performed by applying bacterial inoculum at saturating $\left(10^{6}\right.$ per $\mathrm{ml}$ or root) and unsaturating ( $10^{2}$ per $\mathrm{ml}$ or root) concentrations. The individual strains were adjusted to the appropriate cell density and mixed in different proportions based on a simplex design (Kirwan et al. 2007). Due to differences in what we intended to add as inoculum and the actual cell counts on plates, the proportional mixtures of cells were corrected for and used in comparison of nodule occupancy by the individual strains. Germinated seedlings were transferred to sterilized Magenta jars (Sigma, St Louis, MO, USA) containing washed vermiculite saturated with Broughton's N-free nutrient solution (Broughton and Dilworth 1970). Vermiculite was washed three times with tap water and soaked overnight in nitrogenfree Broughton's solution. This was then used to fill the jars. Five sterilised seedlings of clover $(2 \mathrm{~d}$ old $)$ were planted in each jar and grown under supplemented light from Phillips HPI/T $400 \mathrm{~W}$ lamps (Philips, Turnhout, Belgium) with $17 \mathrm{~h}$ photoperiod at $25^{\circ} \mathrm{C}$. Each plant was aseptically inoculated with $1 \mathrm{ml}$ of inoculum mixture. After inoculation, the plants were further incubated in the growth room. Nodulation was assessed 4 weeks after planting. Nodules on the roots were surface sterilized in $70 \%$ ethanol and $6 \% \mathrm{H}_{2} \mathrm{O}_{2}$ with a drop of Tween 20 (Merck, Darmstadt, Germany). Preparations of nodule and cell suspensions were as described previously (Svenning et al. 2001).

DNA fingerprinting of isolates

Nodule isolates and crushed nodules were individually screened by ERIC DNA PCR fingerprinting (Versalovic et al. 1991; de Bruijn 1992). The PCR amplification reaction was performed in a total volume of $25 \mu \mathrm{l}$ containing $1 \mu \mathrm{l}$ of bacterial cell suspension or crushed nodule as a template, $18 \mu \mathrm{l}$ of sterile MilliQ water, $2.5 \mu$ of $10 \times$ reaction buffer for DynaZyme polymerase (Finnzymes Oy, Espoo, Finland), $1.0 \mu \mathrm{l}$ of 50 pmol each of ERIC 1 and ERIC 2 primers (Eurogentec, Seraing, Belgium), $0.5 \mu \mathrm{l}$ of $10 \mathrm{mM}$ dNTP mix F-560L (Finnzymes Oy, Espoo, Finland) and $1.0 \mu \mathrm{l}$ of DynaZyme ${ }^{\mathrm{TM}}$ DNA polymerase $(2 \mathrm{U} / \mu \mathrm{l})$ F-501, (Finnzymes Oy, Espoo, Finland). The cycling condition was as described by de Bruijn (1992). Twelve micro-litre of the PCR amplified DNA products were loaded onto $1.5 \%$ Seakem ${ }^{\circledR} \mathrm{LE}$ agarose (FMC BioProducts, Rockland, Me., USA) gels and run at room temperature in Tris-borate-EDTA (TBE) at $80 \mathrm{~V}$ for $3 \mathrm{~h}$. Ethidium bromide stained gels were photographed using the Gel Doc ${ }^{\mathrm{TM}} 2000$ Gel Documentation System (Bio-Rad, Hercules, California, USA). The ERIC patterns were reproducible and individual isolates were classified into distinct ERIC groups based on visual inspection of their fingerprint patterns.

Root colonisation assay

Root colonisation assays were performed according to the method described by Jensen et al. (2005). Briefly, white clover seeds were surface sterilized and germinated as described before. Seedlings were transferred singly to sterilized Magenta jars (Sigma) containing sterile vermiculite and inoculated with 100-200 bacterial cells per root. Each treatment had five plants in triplicate with three jars per replicate. At 
seven days after inoculation, roots were harvested under sterile conditions and sonicated for $10 \mathrm{~min}$ in ice-cold buffer $(0.05 \mathrm{M}$ phosphate [pH 7.2] containing $0.01 \%$ (wt/vol) Tween and vortexed for $30 \mathrm{~s}$ at maximum speed. Appropriate dilutions of these suspensions were plated out onto TY medium and the individual cells recovered from the root surface were screened by ERIC PCR DNA fingerprinting (de Bruijn 1992). Experiments were repeated at least twice.

\section{Nodule efficiency test}

Sterilised pre-germinated clover seedlings ( $2 \mathrm{~d}$ old $)$ were transferred from water agar plates to plastic growth pouches (North-rup King Seed Co., Minneapolis, MN). Each pouch contained 5 plants, with 10 pouches per treatment. The pouches were moistened with $10 \mathrm{ml} \mathrm{N}$ free Broughton's nutrient solution. In order to prevent drying and to maintain sterility, seedlings in growth pouches were placed very close together in boxes and covered with aluminium foil until inoculation. Roots of individual seedlings were inoculated $3 \mathrm{~d}$ after transfers to pouches with $100 \mu \mathrm{l}$ of an appropriate dilution of the bacterial suspension by dripping slowly on its surface. Prior to inoculation, the position of the root tip (RT) and the smallest emerging root hairs were marked under a dissecting microscope (Bhuvaneswari et al. 1981). Plants were grown in a growth chamber at temperature of $25^{\circ} \mathrm{C}$, with a photoperiod of $17 \mathrm{~h}$. The pouches were moistened with sterile nitrogen free Broughton's solution as required. The number and relative location of nodules on the main roots were determined $10 \mathrm{~d}$ after inoculation using a dissecting microscope. Experiments were repeated at least twice with 100 replicate plants in each treatment.

Construction of GFP and DsRed marked Rlt strains for infection studies

The two Rlt strains (strain 20-15 and strain 32-28) were cross tagged with GFP and DsRed fluorescent proteins by mating plasmids pDG70 or pDG77 (Gage 2002) into these strains by tri-parental mating as described by Jensen et al. (2005). All bacteria used in mating were grown to late log phase. Transconjugants were selected on TY medium plates containing polymyxin $(20 \mu \mathrm{g} / \mathrm{ml})$ and tetracycline $(5 \mu \mathrm{g} / \mathrm{ml})$. Mutant strains expressing GFP and DsRed proteins gave green and red fluorescence, respectively, under fluorescence microscope. The stability of plasmids in the absence of antibiotics was tested by growing the GFP and DsRed marked strains through successive generations in TY liquid at $28^{\circ} \mathrm{C}$, and plating serial dilutions of cultures on non-selective plates. Plasmid loss was scored by counting the number of colonies that showed no green or red fluorescence. The marked strains were inoculated and reisolated from nodules to check for plasmid stability during symbiosis. We also compared the growth rate of the fluorescent tagged and unmarked strains by periodically measuring the optical density (OD) at $\mathrm{A}_{600}$ over 4 d (data not shown).

\section{Competition at root-hair infection stage by GFP} and DsRed marked strains

Clover seedlings were established in Magenta jars and in growth pouches as described above. Plant roots were inoculated with 1:1 mixture of the marked strains at a density of $10^{5}$ cells per Magenta jar or growth pouch. Conditions of plant growth were as described before. The number of infection threads and nodules expressing GFP and DsRed on each root were scored after a minimum of $10 \mathrm{~d}$. In separate experiments, plants were inoculated with 1:1 mixture of GFP tagged and untagged wild-type strains and nodules were allowed to develop for 21-30 d. Selected nodules were surface sterilised, crushed and observed for green fluorescent bacteria under the microscope.

\section{Microscopy}

Plants roots inoculated with fluorescent marked bacteria were mounted in de-ionized water on a cover slip and observed under a Leitz DAS (DM RB/E) microscope equipped with epifluorescence detection. Filter sets tailored to the specific chromophores were used. GFP expression was recorded using the GFP filter cube with BP470/40 excitation filter and BP525/ 50 suppression filter. DsRed fluorescence was monitored using the excitation filter BP515-560 and suppression filter LP590. Images were obtained using confocal laser scanning microscope (LSM510 META, Carl Zeiss, Germany). GFP was excited using the $488 \mathrm{~nm}$ laser line and emission detected using the 500 to $530 \mathrm{~nm}$ band pass filter. DsRed was excited using the $543 \mathrm{~nm}$ laser line and emission detected using the $560 \mathrm{~nm}$ long pass filter. 
Fig. 1 ERIC-PCR finger-

print patterns generated from cells and crushed nodule suspensions showing nodule occupancy of tested strains on white clover. Rlt (20-15, 8-9 32-28) are the standard reference patterns of the three tested strains. a, $\mathrm{b}$ and $\mathrm{c}$ represent identified patterns from crushed nodules following inoculation of plants with mixtures of the three strains. pGEM is a Molecular marker,

(Promega)

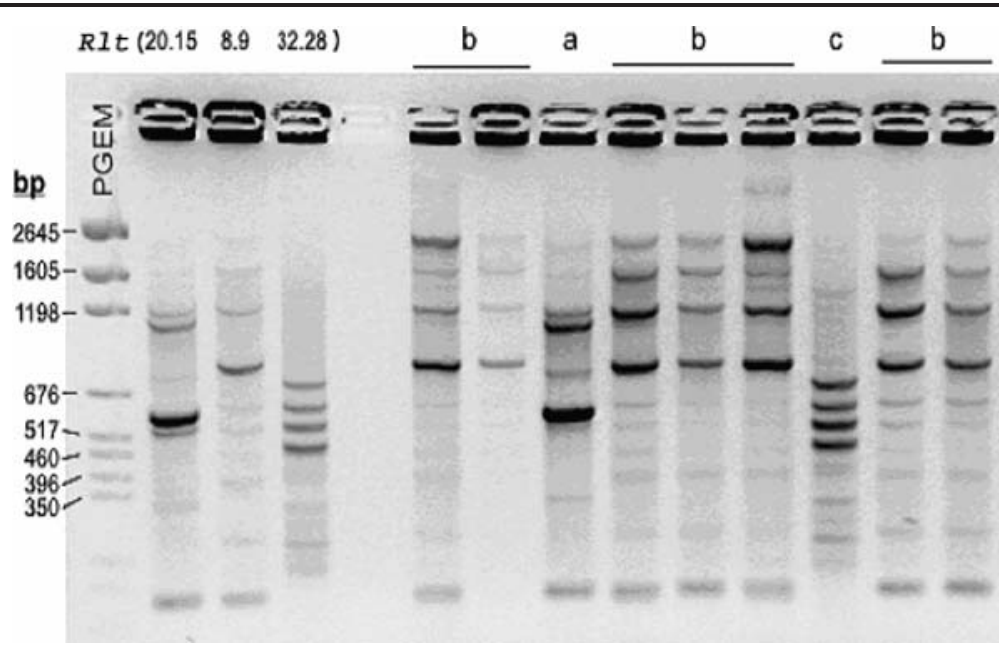

\section{Statistical analysis}

We examined the number of nodules infected by each strain and tested for deviations from the proportion of each strain present initially in the inoculum using a multinomial base-line category analysis (Agresti 2002). The competitiveness of each strain is expressed as the proportion of nodules occupied by the strain relative to the initial proportion of that strain in the inoculum.

Significant differences between treatment means of the root colonisation and infection data were deduced by Chi-square tests (Wardlaw 2000) using the MINITAB statistical program (Minitab Inc., Coventry, U.K.).

\section{Results}

The nodulation competitiveness of the three Rlt strains was assessed at different inoculum combinations and cell densities under controlled conditions. The ERIC fingerprints of the strains for identification are shown in Fig. 1. The analysis showed a significant change in composition from the initial proportion of each strain in the inoculum to their final nodule occupancy (Fig. 2). Even though there was a general tendency for higher nodule occupancy by each strain with increase in cell numbers, Rlt 20-15 consistently had a greater relative nodule occupancy than expected (i.e. had a relative value greater than 1 for all treatments) (Table 1), Rlt 32-28 failed to achieve its expected nodule occupancy in all inoculum combinations tested (values less than 1 in Table 1), Rlt 8-9 on the other hand, showed an inconsistent pattern of change, with some relative values greater than expected but others less than expected (Table 1). At non-saturating levels of $10^{2}$ cells per root (where bacteria have to competitively colonize the root

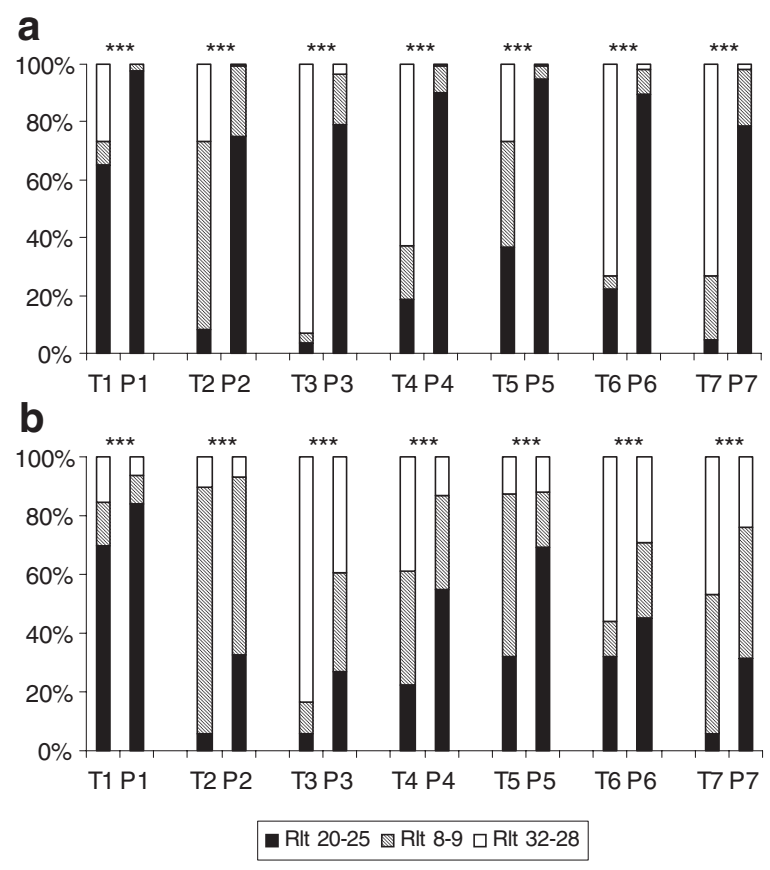

Fig. 2 Competition for nodule occupancy on white clover by the individual Rlt strains at (a) a non saturating inoculum density of $10^{2}$ cells per root and (b) a saturating inoculum density of $10^{6}$ cells per root. T1-7 represents the proportions of each strain present in the initial inoculum mixtures. P1-7 represents the proportion of nodules each strain infected. Significant differences between the proportions in $\mathrm{T}$ and $\mathrm{P}$ are indicated by stars above the pair of bars for each density by initial inoculum mixture proportion combination $(* \mathrm{p}<0.1 ; * * \mathrm{p}$ $<0.05$; *** $\mathrm{p}<0.01$ ) 
Table 1 Change in strain composition

\begin{tabular}{|c|c|c|c|c|c|c|}
\hline \multirow[t]{2}{*}{ Initial Density } & \multicolumn{3}{|c|}{ Initial proportion in the inoculum for each strain } & \multicolumn{3}{|c|}{ Proportion of nodules infected relative to the initial proportion } \\
\hline & Rlt 20-25 & Rlt 8-9 & Rlt $32-28$ & Rlt $20-25$ & Rlt 8-9 & Rlt $32-28$ \\
\hline \multirow[t]{7}{*}{$10^{2}$ cells/ root } & 0.65 & 0.08 & 0.27 & 1.52 & 0.19 & 0.01 \\
\hline & 0.08 & 0.65 & 0.27 & 10.03 & 0.28 & 0.01 \\
\hline & 0.03 & 0.03 & 0.93 & 18.47 & 9.59 & 0.02 \\
\hline & 0.19 & 0.19 & 0.63 & 5.02 & 0.29 & 0.01 \\
\hline & 0.36 & 0.36 & 0.27 & 2.67 & 0.06 & 0.01 \\
\hline & 0.22 & 0.05 & 0.73 & 4.39 & 0.64 & 0.01 \\
\hline & 0.05 & 0.22 & 0.73 & 14.12 & 1.33 & 0.03 \\
\hline \multirow[t]{7}{*}{$10^{6}$ cells/root } & 0.70 & 0.15 & 0.15 & 1.18 & 0.85 & 0.33 \\
\hline & 0.06 & 0.84 & 0.10 & 5.76 & 0.72 & 0.55 \\
\hline & 0.06 & 0.10 & 0.84 & 6.63 & 2.62 & 0.39 \\
\hline & 0.22 & 0.39 & 0.39 & 2.52 & 0.91 & 0.23 \\
\hline & 0.32 & 0.56 & 0.12 & 2.02 & 0.58 & 0.27 \\
\hline & 0.32 & 0.12 & 0.56 & 2.25 & 1.28 & 0.22 \\
\hline & 0.06 & 0.47 & 0.47 & 4.66 & 1.23 & 0.31 \\
\hline
\end{tabular}

The three columns in the left hand panel show the initial proportions of the three strains for fourteen experimental treatments. The three columns in the right hand panel show the estimated final proportion of total nodules occupied by each strain relative to this initial proportion. A value of 1 indicates no change from initial proportion, while a value greater (less) than 1 indicates that the strain competed well (poorly). Composition shifted significantly during the course of the experiment for all treatments $(p<0.01)$

surface before nodulating), Rlt 20-15 formed most of the nodules and Rlt 32-28 formed the least. When the strains were inoculated at saturating concentrations of $10^{6}$ cells per root, there was a decrease in the relative dominance of Rlt 20-15, while the relative nodule occupancy of Rlt 32-28 increased.

The strong nodulation dominance of Rlt 20-15 at low inoculum application, suggested that either it multiplies rapidly on the host root rhizosphere or needs a fewer number of cells to initiate infections. Likewise the increase in relative nodule occupancy of Rlt 32-28 at saturating inoculum concentrations suggests that Rlt 32-28 might have competed poorly at colonization stage. To test for colonization, we examined the ability of Rlt 32-28 to compete against Rlt 20-15 for growth on the plant roots as described in Materials and Methods. The results indicated no significant differences between the two tested strains in root colonization either in competitive or in non-competitive situations (Table 2). When nodule initiation efficiency of these strains were examined (Fig. 3), the nodulation response curve was nearly linear up to $10^{5}$ inoculum

Table 2 Competitive root colonization of white clover roots between Rlt 20-15 and Rlt 32-28

\begin{tabular}{|c|c|c|c|c|c|}
\hline \multirow[t]{2}{*}{ Strain mixture ratio (Rlt $20-15 /$ Rlt $32-28$ ) } & \multirow[t]{2}{*}{ Total cells ${ }^{\text {a }}$} & \multirow[t]{2}{*}{ Rlt $20-15$ cells $^{\text {a }}$} & \multirow[t]{2}{*}{ Rlt $32-28$ cells $^{\text {a }}$} & \multicolumn{2}{|c|}{ Rlt $20-15$ in total $(\%)^{\mathrm{b}}$} \\
\hline & & & & Expected & Observed \\
\hline $1: 1$ & $65.5(6.3)$ & $34.2(4.9)$ & $31.3(5.5)$ & 50 & $52 \mathrm{a}$ \\
\hline $1: 9$ & $92.3(18.2)$ & $9.0(2.6)$ & $83.3(19.2)$ & 11 & $9.8 \mathrm{a}$ \\
\hline $1: 0$ & $65.0(12.1)$ & NA & NA & NA & NA \\
\hline $0: 1$ & $66.7(12.0)$ & NA & NA & NA & NA \\
\hline
\end{tabular}

${ }^{\mathrm{a}}$ The numbers represent average bacterial cells per root $\left(10^{4}\right)$ of 90 plants from two experiments. The standard deviations are given in parentheses.

${ }^{b}$ Treatments followed by the same letter are not significantly different at the $95 \%$ confidence level.

NA, not applicable 


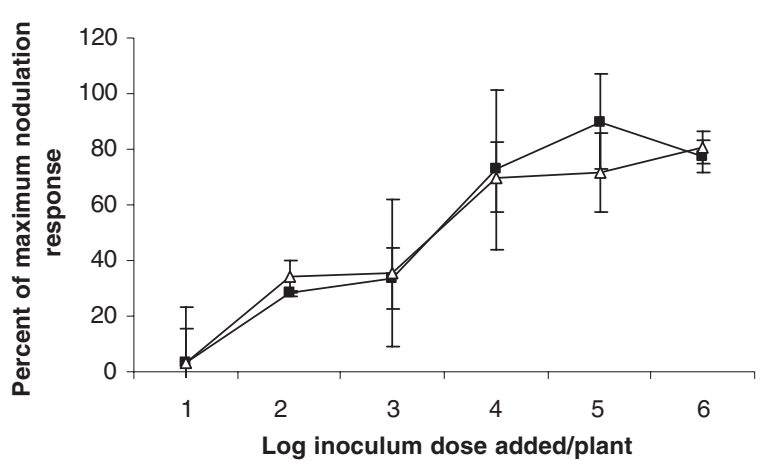

Fig. 3 Inoculum dose-nodulation response of Rlt 20-15 (घ) and Rlt 32-28 $(\Delta)$ with white clover. Plants were inoculated with $100 \mu \mathrm{l}$ of bacterial suspension at the indicated dosage per plant. Nodules on primary root above the root tip mark were determined 10 days after inoculation. Data are shown as means \pm SD from two experiments with each point representing averages from $90-100$ plants

levels, but declined at higher inoculum dosages for Rlt 20-15. On the other hand, the nodulation response of Rlt 32-28 maintained a more or less linear fashion, and did not reduce at inoculum density above $10^{5}$ bacterial cells. Both strains, however, required the same number of cells to generate half-maximal nodulation response, suggesting that they are equally efficient in initiating nodule formation.

In order to define the stage of nodulation where the competitiveness of strain 20-15 occurs, we followed infection of the root hair in vivo with Rlt 20-15 marked with GFP fluorescence protein and Rlt 32-28 marked with DsRed fluorescence protein and vice versa. Prior to this investigation, we compared nodulation of the fluorescent marked strains with their parental strains. When these were tested at 1:1 inoculum ratio, both marked and parent strains formed similar numbers of nodules that were pink in colour (data not shown). This indicates that the insertion of plasmids expressing the fluorescent proteins did not alter the symbiotic properties or competitiveness of the parental strains. No growth differences were observed between the marked and unmarked strains based on their mean generation times (data not shown). In some of these competition experiments the fluorescent tags were reversed for the strains used. Regardless of the fluorescent tags used, Rlt 20-15 significantly formed more infection threads and nodules than Rlt 32-28 when co-inoculated onto the plant root. Of the 34 roots screened, $76.1 \%$ (217 out of 285 infection threads observed) of the infections were formed by Rlt $20-15$, and the rest by Rlt $32-28$.
Among the 302 nodules screened, $87.1 \%$ were occupied by Rlt $20-15$ and $12.9 \%$ by Rlt $32-28$. We did not observe any infection threads or nodules occupied by both strains (Fig. 4).

\section{Discussion}

The goal of this study was to understand the basis for the differential competitiveness of three defined strains of Rhizobium on their plant hosts by specifically analysing for the critical stage(s) in the nodulation process where the competition has most likely occurred. Results presented in Table 2, indicates that differences in the initial multiplication and colonisation of the root surfaces is not the cause for differential nodulation competitiveness of the three strains tested. Our results are consistent with other reports from earlier studies (Leung et al. 1994). We tested these three strains in vitro for specific bactericidal or bacteriostatic effect towards each other and found that none of the three tested strains inhibited the growth of the others (data not shown). Equal colonization of the root by Rlt 20-15 and 32-28 suggests that the competitiveness of the Rlt 20-15 is expressed after root colonisation stage, possibly inside the root hair. This suggestion is supported by data from our root hair infection studies where the most competitive strain (Rlt 20-15) formed significantly higher number of infections than the least competitive strain (Rlt 32-28), and relative nodule numbers more or less corresponded to the relative number of infections for Rlt 20-15. On the other hand, about $25 \%$ of the infection threads observed and $13 \%$ of the nodules screened were occupied by Rlt 32-28. The competitiveness of Rlt 20-15 can be expressed either at infection thread initiation or during bacterial growth in the infection threads. Similar observations have recently been reported from competition studies between wild-type and trehalose utilization mutant strains on alfalfa roots (Jensen et al. 2005). Since rhizobia are not mobile in the infection thread, the rate of multiplication of bacteria inside the infection thread determines the rate of infection thread proliferation (Gage 2002) and subsequent nodule occupancy. Processes that contribute to improved fitness of the bacteria inside the infection thread therefore may contribute to enhanced nodulation competitiveness. 

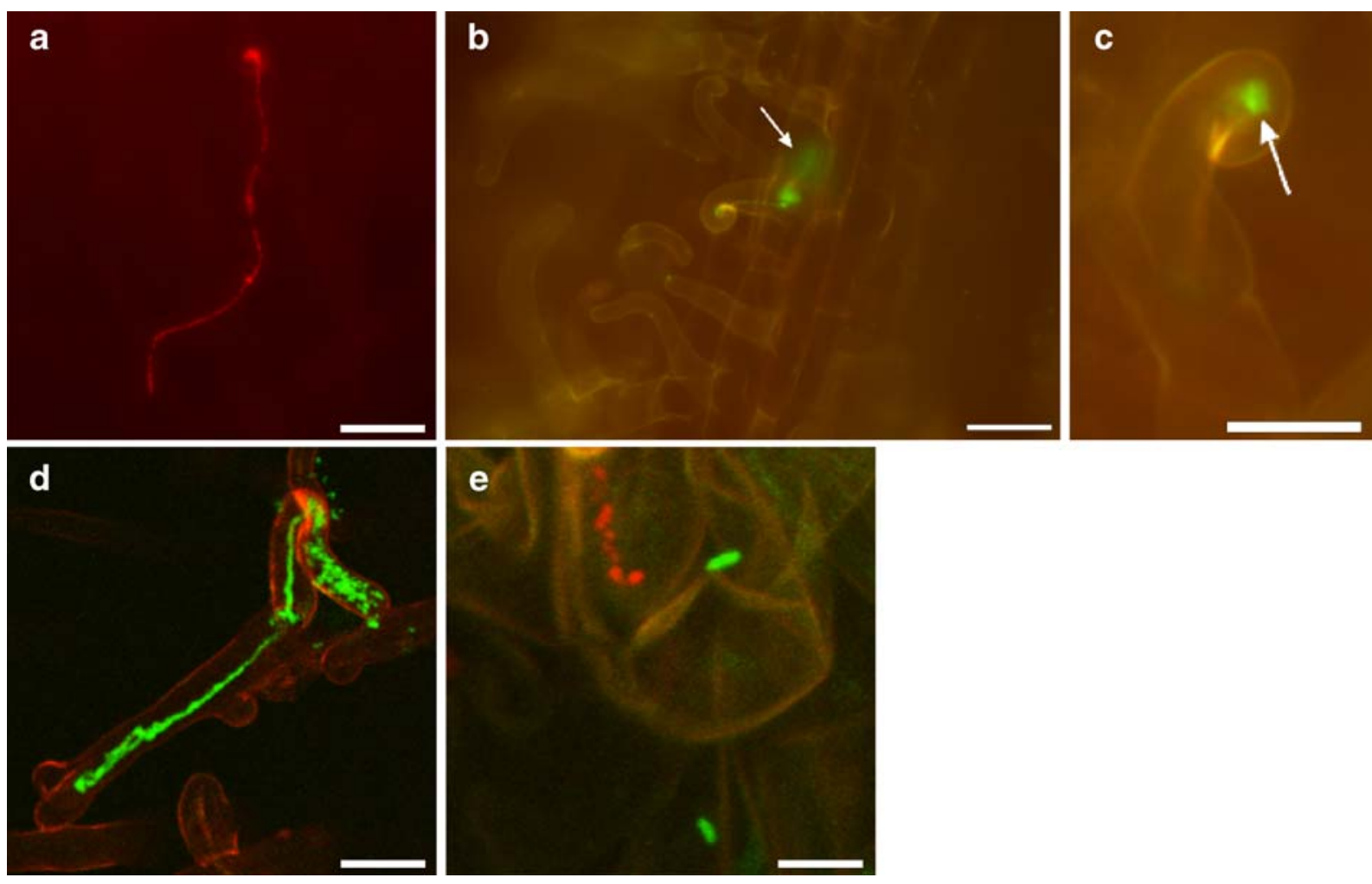

Fig. 4 Examples of infection events following coinoculation of white clover roots with red- and green-fluorescent tagged Rlt strains. a Infection thread containing DsRed-expressing Rlt 3228. b Infection thread leading to a nodule in the inner root tissue (arrowed) containing GFP-expressing Rlt 20-15. c Curled root hair with green microcolonies (arrowed) induced by GFP-

At present, the environmental conditions inside the infection thread determining the multiplication and growth of rhizobia in the infection thread are not known. It is shown that active growth of the symbiont occurs only near the tip of the infection threads in a very small zone and that rhizobial strains that catabolize specific substrate(s) in the infection thread may grow faster and initiate the nodule primordia quickly (Gage 2002). Therefore, we contend that stains with improved competitiveness, may grow more rapidly in the infection thread, to initiate and infect the nodule primordia faster. Since there is a stringent regulation of nodule numbers by the host, such competitive growth might block less competitive ones from completing the infection events and occupying the nodule. The observation that the number of nodules occupied by Rlt 32-28 corresponds to only about $50 \%$ of infection threads supports this hypothesis. expressing Rlt 32-28 that failed to give rise to an infection thread. d Infection thread colonised by GFP-expressing Rlt 2015 in a root hair e Single cells of GFP- expressing Rlt 32-28 and a short infection thread colonised by DsRed expressing Rlt $20-15$, on the root surface and inside the root hair, respectively. Bar $50 \mu \mathrm{m}$

Generally, rhizobia are exposed to different stress factors during early interactions in symbiosis with the host plant. In alfalfa infections, $S$. meliloti mutants with impaired mechanism to cope with oxidative stress are unable to multiply in the infection threads (Herouart et al. 2002). Recently, Jensen et al. (2005) demonstrated that $S$. meliloti is exposed to osmotic stress in the infection threads, and mutant strains with ability to accumulate trehalose in their cells enhanced their nodulation competitiveness via increased number of infections. Also, it was shown that ethylene negatively regulates rhizobial infection and nodulation (Zaat et al. 1989; Okazaki et al. 2004), and strains with greater ability to overcome ethylene stress during infection showed enhanced nodulation competitiveness (Ma et al. 2004). Taken together, these observations suggest that strains with better stress adaptation may show greater competitiveness for nodule occupancy. Whether the competitiveness of $R l t$ 
$20-15$ is related to its better stress coping ability during growth inside the root hair is yet to be determined.

The results presented in this study show that the competitiveness of Rlt 20-15 is not due to its superior root colonization but may be related to its ability to grow better in the infection threads. This strain is among few native strains that maintain similar levels of nodulation competitiveness in the laboratory and under certain field conditions, and may be useful as a model organism for an in-depth analysis of microbial competition and to study the factors that influence growth inside the infection threads.

Acknowledgements This work was supported by the Norwegian Research Council grant (126312/110), as part of NKJ (Nordic Joint Committee for Agricultural Research) project 106- Exploring legume-Rhizobium symbioses for sustainable agriculture. Travel support to Ireland for the statistical analysis was funded by COST 852 short-term scientific missions. We thank Dr. Daniel J. Gage at the University of Connecticut, USA, for kindly providing us with the GFP and DsRed plasmids. Coby Weber is thanked for her technical assistance.

\section{References}

Agresti A (2002) Categorical Data Analysis, 2nd edn. Wiley, New Jersey

Bhuvaneswari TV, Bhagwat AA, Bauer WD (1981) Transient susceptibility of root cells in four common legumes to nodulation by rhizobia. Plant Physiol 68:1144-1149

Brockwell J, Bottomley PJ, Thies JE (1995) Manipulation of rhizobia microflora for improving legume productivity and soil fertility: a critical assessment. Plant Soil 174:143-180. doi:10.1007/BF00032245

Brockwell J, Gault RR, Morthorpe LJ, Peoples MB, Turner GL, Bergersen FJ (1989) Effects of soil nitrogen status and rate of inoculation on the establishment of populations of Bradyrhizobium japonicum and on the nodulation of soybeans. Aust J Agric Res 40:753-762

Broughton WJ, Dilworth MJ (1970) Plant nutrient solutions: In Somasegaran P, Hoben HJ (eds) Methods in LegumeRhizobium Technology-Handbook for rhizobia Niftal Project, Univ. of Hawaii. pp 245-249

de Bruijn FJ (1992) Use of REP (Repetitive Extragenic Palindromic and Enterobacterial Repetitive Intergenic Consensus) sequences and the polymerase chain reaction to fingerprint the genomes of Rhizobium meliloti isolates and other soil bacteria. Appl Environ Microbiol 58:2180-2187

Dowling DN, Broughton WJ (1986) Competition for nodulation of legumes. Annu Rev Microbiol 40:131-157. doi:10.1146/annurev.mi.40.100186.001023

Duodu S, Bhuvaneswari TV, Gudmundsson J, Svenning MM (2005) Symbiotic and saprophytic survival of three unmarked Rhizobium leguminosarum biovar trifolii strains introduced into the field. Environ Microbiol 7:1049-1058. doi:10.1111/j.1462-2920.2005.00789.x
Duodu S, Carlsson G, Huss-Danell K, Svenning MM (2007) Large genotypic variation but small variation in $\mathrm{N}_{2}$ fixation among rhizobia nodulating red clover in soils of northern Scandinavia. J Appl Microbiol 102:1625-1635. doi:10.1111/j.1365-2672.2006.03196.x

Gage DJ (2002) Analysis of infection thread development using gfp-and DsRed- expressing Sinorhizobium meliloti. J Bacteriol 184:7042-7046. doi:10.1128/JB.184.24.70427046.2002

Herridge DF, Roughley RJ, Brockwell J (1984) Effect of rhizobia and soil nitrate on the establishment and functioning of the soybean symbiosis in the field. Aust J Agric Res 35:149-161. doi:10.1071/AR9840149

Herouart D, Baudouin E, Frendo P, Harrison J, Santos R, Jamet A, Van de Sype G, Touati D, Puppo A (2002) Reactive oxygen species, nitric oxide and glutathione: a key role in the establishment of the legume: Rhizobium symbiosis. Plant Physiol Biochem 40:619-624. doi:10.1016/S09819428(02)01415-8

Jensen JB, Ampomah OY, Darrah R, Peters NK, Bhuvaneswari TV (2005) Role of trehalose transport and utilization in Sinorhizobium meliloti-alfalfa interactions. Mol Plant Microbe Interact 18:694-702. doi:10.1094/MPMI-18-0694

Kirwan LA, Lüscher MT, Sebastià JA et al (2007) Evenness drives consistent diversity effects in intensive grassland systems across 28 European sites. J Ecol 95:530-539. doi:10.1111/j.1365-2745.2007.01225.x

Leung K, Yap K, Dashti N, Bottomley PJ (1994) Serological and ecological characteristics of a nodule-dominant serotype from an indigenous soil population of Rhizobium leguminosarum bv. trifolii. Appl Environ Microbiol 60:408-415

Ma W, Charles TC, Glick BR (2004) Expression of an exogenous 1-aminocyclopropane-1-carboxylate deaminase gene in Sinorhizobium meliloti increases its ability to nodule alfalfa. Appl Environ Microbiol 70:5891-5897. doi:10.1128/AEM.70.10.5891-5897.2004

Merrick MJ, Edwards RA (1995) Nitrogen control in bacteria. Microbiol Rev 59:604-622

Okazaki S, Nukui N, Sugawara M, Minamisawa K (2004) Rhizobial strategies to enhance symbiotic interactions: Rhizobitoxine and 1-aminocyclopropane-1-carboxylate deaminase. Microbes Environ 19:99-111. doi:10.1264/ jsme2.19.99

Sessitsch A, Howieson JG, Perret X, Antoun H, MartínezRomero E (2002) Advances in Rhizobium Research. Crit Rev Plant Sci 21:323-378. doi:10.1080/0735260291044278

Somasegaran P, Hoben HJ (1994) Handbook for Rhizobia: Methods in Legume-Rhizobium Technology. SpringerVerlag, New York, pp 366-369

Svenning MM, Gudmundsson J, Fagerli I-L, Leinonen P (2001) Competition for nodule occupancy between introduced strains of Rhizobium leguminosarum biovar trifolii and its influence on plant production. Ann Bot (Lond) 88:781787. doi:10.1006/anbo.2001.1484

Triplett EW, Sadowsky MJ (1992) Genetics of competition for nodulation of legumes. Annu Rev Microbiol 42:399-428. doi:10.1146/annurev.mi.46.100192.002151

Young RR, Brockwell J (1992) Influence of soil pH on the development of symbiosis in field-grown acid-sensitive 
and acid-tolerant annual medics. Aust J Exp Agric 32:167-173. doi:10.1071/EA9920167

Versalovic J, Koeuth T, Lupski JR (1991) Distribution of repetitive DNA sequences in eubacteria and application to fingerprinting of bacterial genomes. Nucleic Acids Res 19:6923-6831. doi:10.1093/nar/19.24.6823

Vlassak KM, Vanderleyden J (1997) Factors influencing nodule occupancy by inoculant rhizobia. Crit Rev Plant Sci 16:163-219. doi:10.1080/713608146
Wardlaw AC (2000) Practical statistics for experimental biologists, Second edition. John Wiley \& Sons, Ltd., New York, N. Y

Zaat SAJ, van Brussel AAN, Tak T, Lugtenberg BJJ, Kijne JW (1989) The ethylene-inhibitor aminoethoxyvinylglycine restores normal nodulation by Rhizobium leguminosarum biovar viciae on Vicia sativa subsp. nigra by suppressing the 'Thick and short roots' phenotype. Planta 177:141150. doi:10.1007/BF00392802 